MECHANISMS IN ENDOCRINOLOGY

\title{
Neurodevelopmental disorders in children born to mothers with thyroid dysfunction: evidence of fetal programming?
}

\author{
Stine Linding Andersen ${ }^{1,2}$, Allan Carlé1, Jesper Karmisholt ${ }^{1}$, Inge Bülow Pedersen ${ }^{1}$ \\ and Stig Andersen ${ }^{3,4}$ \\ Departments of ${ }^{1}$ Endocrinology, ${ }^{2}$ Clinical Biochemistry, and ${ }^{3}$ Geriatrics, Aalborg University Hospital, Aalborg, \\ Denmark, and ${ }^{4}$ Department Clinical Medicine, Aalborg University, Aalborg, Denmark
}

Correspondence should be addressed to $S \mathrm{~L}$ Andersen

Email

stine.a@rn.dk

\begin{abstract}
Fetal programming is a long-standing, but still evolving, concept that links exposures during pregnancy to the later development of disease in the offspring. A fetal programming effect has been considered within different endocrine axes and in relation to different maternal endocrine diseases. In this critical review, we describe and discuss the hypothesis of fetal programming by maternal thyroid dysfunction in the context of fetal brain development and neurodevelopmental disorders in the offspring. Thyroid hormones are important regulators of early brain development, and evidence from experimental and observational human studies have demonstrated structural and functional abnormalities in the brain caused by the lack or excess of thyroid hormone during fetal brain development. The hypothesis that such abnormalities introduced during early fetal brain development increase susceptibility for the later onset of neurodevelopmental disorders in the offspring is biologically plausible. However, epidemiological studies on the association between maternal thyroid dysfunction and long-term child outcomes are observational in design, and are challenged by important methodological aspects.
\end{abstract}

\section{Introduction}

Thyroid hormones are important developmental factors and crucial during early brain development (1). Development of the human brain is a tightly regulated and complex process that extends beyond the pregnancy period (2). It is genetically encoded and prone to disturbances by prenatal and postnatal exposures. Evidence from in vitro and in vivo studies have demonstrated the important role of thyroid hormones in brain development. In cerebellar cell cultures, dendritic growth of Purkinje cells was significant in the presence

\section{Invited Author's profile}

Stine Linding Andersen, MD, PhD is a junior doctor and senior research fellow at the Departments of Clinical Biochemistry and Endocrinology, Aalborg University Hospital, Aalborg, Denmark. She is undergoing medical specialist training within the field of clinical biochemistry. Her research mainly focuses on iodine status and thyroid disease in and around pregnancy. Furthermore, a main area of interest has been the risk of birth defects associated with the use of antithyroid drugs in pregnancy. More recently, her research has included biochemical measurements of maternal thyroid function in early pregnancy.

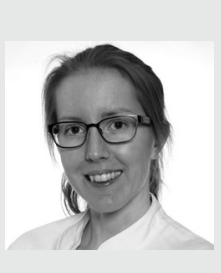

() 2017 European Society of Endocrinology Printed in Great Britain
Published by Bioscientifica Ltd. 
of T3 or T4, but not in the absence of thyroid hormones $(3,4)$. In rats, studies have demonstrated the structural and functional consequences of maternal thyroid dysfunction on the fetal brain including alterations in the neuronal proliferation, migration, differentiation, synaptogenesis and myelination $(1,2,5)$.

In humans, the most severe and adverse effect of maternal hypothyroidism on fetal brain development is evident from the neurological symptoms of endemic cretinism (6). Recent studies including data on brain MRI scans from children born to mothers with thyroid dysfunction have demonstrated structural defects in the brain $(7,8,9,10,11)$. However, most studies in humans include indicators of exposure or outcome and are observational in design, which may challenge the interpretation of the results.

Neurodevelopmental disorders develop secondary to disruption of early brain development (12). Depending on the cause and timing of exposure, the symptoms of neurodevelopmental disorders may vary and may range from specific disabilities to global impairments. The causes are far from understood, and the diseases are generally considered of multifactorial origin (13). A proposed mechanism is 'the fetal origin hypothesis' that links exposures during fetal life with the later development of disease (14). Considering the crucial role of maternal thyroid hormones during early brain development, a pertinent question is whether abnormal maternal thyroid function in pregnancy via subtle changes during early brain development can program the fetus to neurodevelopmental disease.

In this critical review, we describe the concept of fetal programming and the hypothesis of fetal programming by maternal thyroid dysfunction. We discuss the evidence of this hypothesis in relation to brain development and neurodevelopmental disorders in the offspring and address the methodological challenges.

\section{Fetal origin hypothesis}

The first description of a possible fetal programming effect emerged from Norway and was published in 1977 (15). In this study, Forsdahl showed that cardiovascular mortality in men aged 40-69 years was higher if they had been born in regions where infant mortality at that time was high. He believed that this was due to poor living conditions. The study by Barker et al. showed that the link was birth weight and proposed the fetal origin hypothesis in 1989 (16). They showed that men with the lowest birth weight and weight at 1 year of age had the highest mortality rate due to ischemic heart disease and a higher frequency of impaired glucose tolerance at the age of 60-70 years (16). These findings led to the suggestion of 'the thrifty phenotype hypothesis' for the development of type 2 diabetes (17). Adaptation to poor nutrition in fetal life may lead to permanent changes in the function of organs, which would be beneficial if nutrition remained poor after birth. However, if nutrition becomes plentiful later, the adaptive changes may predispose to development of disease in obese individuals. This interaction between prenatal and postnatal exposure has also been shown in study periods with extreme shortage of food e.g. exposure to the Dutch (18) and Chinese famine (19) in fetal life was associated with a higher risk of type 2 diabetes in adulthood. This association was exacerbated by high socioeconomic status, BMI and western dietary pattern. About the time of 'the thrifty phenotype hypothesis', a programing effect on the later development of other diseases was proposed. The study by Ekbom et al. (20) from Sweden published in the year 1992 showed that high birth weight was a risk factor and that maternal preeclampsia was a protective factor for later development of breast cancer. The concept of fetal programing has been extensively studied during the following decades, and fetal programing has been considered within many different endocrine axes (Table 1). The field is intriguing and complex because endocrine diseases can be considered as the exposure during the pregnancy, but also as the outcome in the offspring. Diabetes is the most common endocrine disease, and the concept of fetal programing has long been considered in relation to this disease (21, 22). As mentioned above, some of the initial studies within this field observed a link between exposures in pregnancy and later development of impaired glucose tolerance or diabetes in the offspring. In contrast, the programing effect of maternal diabetes in the pregnancy on later development of disease in the offspring has been considered, and the main mechanism proposed has been via maternal blood glucose levels $(21,22)$.

Another endocrine axis much considered in the concept of fetal programing is the hypothalamuspituitary-adrenal axis (HPA-axis) in relation to maternal stress and cortisol excess in pregnancy $(23,24)$. Evidence suggests that exposure to high levels of cortisol in utero may alter the set-point of the fetal HPA-axis (23). This may lead to higher cortisol levels in the offspring that may even persist into adult life, and the subtle variation in the HPA-axis activity has been linked to the later 
Table 1 List of endocrine axes and peripheral hormones in which fetal programing has been considered including possible clinical 'clues' and maternal 'conditions'.

\begin{tabular}{|c|c|}
\hline Endocrine axis & Peripheral hormones \\
\hline $\begin{array}{l}\text { HPT-axis (hypothalamus-pituitary- } \\
\text { thyroid) }\end{array}$ & Thyroid hormones (T4 and T3) \\
\hline \multirow{3}{*}{$\begin{array}{l}\text { HPA-axis (hypothalamus-pituitary- } \\
\text { adrenal) }\end{array}$} & Cortisol \\
\hline & $\begin{array}{l}\text { Epinephrine, norepinephrine, } \\
\text { dopamine }\end{array}$ \\
\hline & Aldosterone \\
\hline \multirow[t]{2}{*}{$\begin{array}{l}\text { HPG-axis (hypothalamus-pituitary- } \\
\text { gonadal) }\end{array}$} & Estrogen and progesterone \\
\hline & Testosterone \\
\hline $\begin{array}{l}\text { GH-IGF-1 axis (hypothalamus- } \\
\text { pituitary-liver) }\end{array}$ & Insulin-like growth factor I (IGF-I) \\
\hline Prolactin-axis (hypothalamus-pituitary) & Prolactin \\
\hline \multirow{2}{*}{$\begin{array}{l}\text { Oxytocin/vasopressin-axis } \\
\text { (hypothalamus-pituitary) }\end{array}$} & Oxytocin \\
\hline & Vasopressin \\
\hline \multirow{3}{*}{$\begin{array}{l}\text { PTH-axis (parathyroid gland) } \\
\text { Insulin-glucagon-axis (pancreas) }\end{array}$} & Parathyroid hormone (PTH) \\
\hline & Insulin \\
\hline & Glucagon \\
\hline
\end{tabular}

Clinical 'clues'
Hyper- or hypothyroidism?
Thyroid autoantibodies?
Hypercortisolism?

Catecholamine excess?

Hyperaldosteronism? Hyperandrogenism?

Growth hormone excess?

Hyperprolactinemia? Oxytocin excess?

Vasopressin deficiency/excess?

Hyper- or hypoparathyroidism? Hyperglycemia?
Maternal 'condition'

Thyroid disorders

Cushing's disease

Pheochromocytoma

Conn's syndrome

Polycystic ovary syndrome

Acromegaly

Prolactinoma Exogenous

Diabetes insipidus/ SIADH ${ }^{a}$

Parathyroid disorders Diabetes mellitus

aSyndrome of inappropriate antidiuretic hormone secretion.

development of cardio-metabolic disorders and brain disorders (23).

\section{Hypothesis of fetal programing by maternal thyroid dysfunction}

Considering fetal programing in relation to the hypothalamus-pituitary-thyroid axis (Table 1), this association is similarly complex. Thyroid hormone abnormalities and thyroid autoimmunity have been considered both as the outcome and as the exposure in a fetal programing hypothesis. A number of studies, including studies in twins, have evaluated the association between birth weight and adult thyroid function as the outcome, and some studies have reported an association between fetal growth characteristics and the later presence of thyroid autoantibodies and adult thyroid function $(25,26)$, whereas others found no association $(27,28,29)$.

Recent studies in experimental animals (30) and in humans $(31,32,33)$ have considered thyroid hormone abnormalities as the exposure and cardiovascular function as the outcome. A study in rats (30) suggested that maternal thyroid hormone levels are important in the development of hypothalamic neurons regulating cardiovascular functions. Studies in humans have shown that maternal hypothyroidism may be associated with congenital heart defects in the offspring (32), and that maternal thyroid function in pregnancy may program offspring blood pressure at the age of 20 (33). Still, another study found no association with offspring blood pressure at the age of 6 years (31).

How the lack or excess of thyroid hormone during a pregnancy may influence the fetal development, particularly the fetal brain development, has been studied for decades (1). The fetal thyroid gland is increasingly able to synthesize thyroid hormones in the second half of the pregnancy, and maternal thyroid hormones are critical in the maintenance of a normal pregnancy and in the fetal development, both in the early pregnancy and after the onset of fetal thyroid hormone production $(34,35)$. Thus, the hypothesis of fetal programing by maternal thyroid dysfunction via the role of thyroid hormones in the fetal brain development appears biologically plausible (Fig. 1). The hypothesis is that subtle changes during early brain development may program the fetus to later development of neurodevelopmental disease, and a pertinent consideration is whether the brain abnormalities described after in utero exposure to maternal thyroid dysfunction may coincide with the abnormalities described in neurodevelopmental disorders. However, the association is intriguing due to the multifactorial etiology of both thyroid disorders and neurodevelopmental disorders, and whereas the experimental evidence may be strong, the evaluation of results from observational 


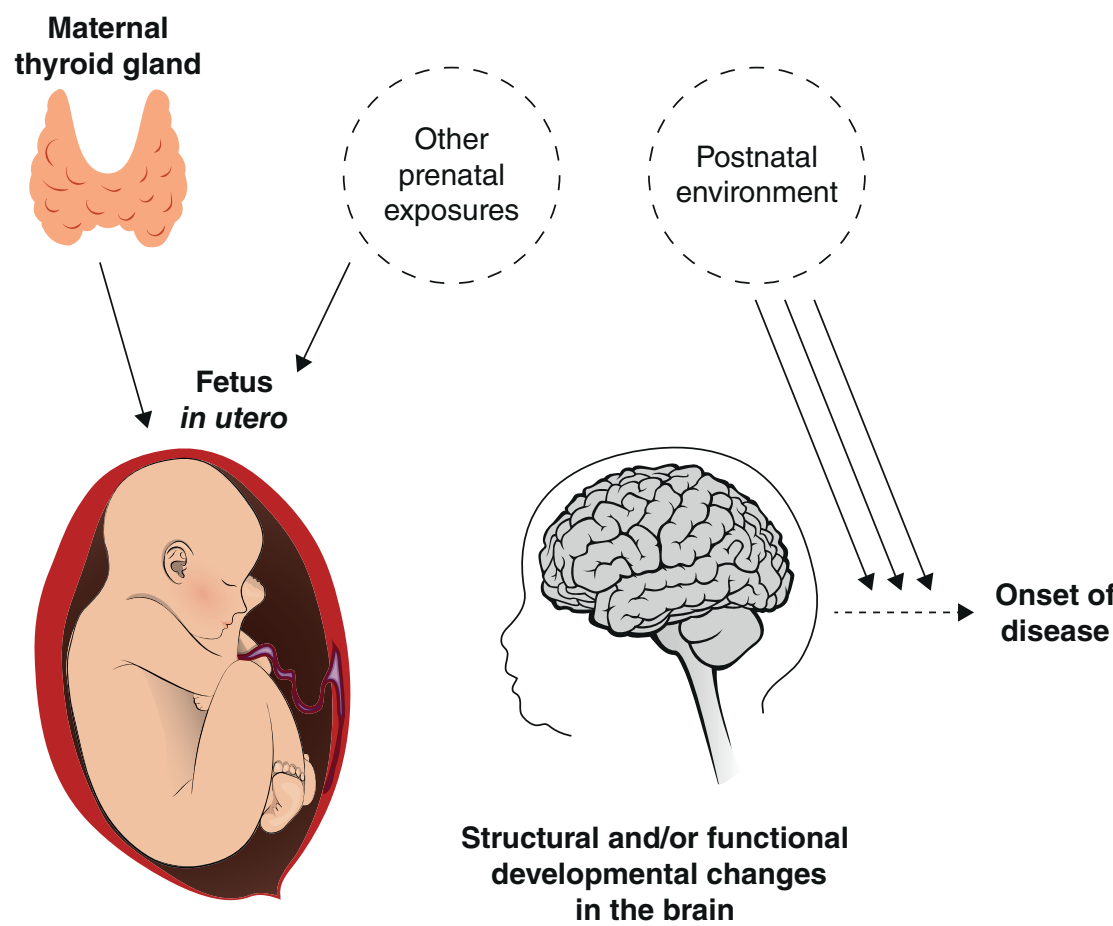

\section{Lack or excess of maternal thyroid hormones during fetal brain development}

studies may be challenged by a long line of many other prenatal and postnatal factors (Fig. 1).

\section{Thyroid hormones and brain development}

Brain development is a complex process that is genetically determined, but also sensitive to the maternal environment. Development of the brain occurs in a series of stages that starts in early fetal life and continues after birth (2). A key characteristic of the brain is that it continues to develop and that the development is plastic. Brain plasticity is the concept that the human brain is able to modify its structure and function in response to the postnatal environment (36). Comprehensive evidence from both in vitro studies of cell cultures and in vivo studies have demonstrated the structural and functional consequences of alterations in the supply of thyroid hormone to the fetal brain during the early developmental period. Structural defects include abnormalities in cell proliferation, migration, differentiation, synaptogenesis and myelination, whereas many of the functional abnormalities relate to alterations in the neurochemical environment in the brain $(1,2,5)$.

Brain development is a highly regulated process and an important part of this regulation includes the coordinated and timely expression of many different

\section{Figure 1}

Illustration of the hypothesis of fetal programing by maternal thyroid dysfunction. The hypothesis is challenged by other potential prenatal exposures and by interaction with the postnatal environment.

genes. Thyroid hormones are important developmental factors and their crucial role in early brain development is facilitated via the regulation of gene expression (37). T3 binds to nuclear thyroid hormone receptors, and recent in vitro studies have identified genes of primary cerebrocortical cells that are regulated transcriptionally by $\mathrm{T} 3(38,39)$.

One of the oldest observations in humans on the adverse effects of abnormal maternal thyroid function in pregnancy on fetal brain development is the neurological symptoms of cretinism (6). Endemic cretinism is a disorder of profound mental and physical disability that develops as a consequence of severe iodine deficiency (6). Distinct clinical types of the disorder have been described and it has been proposed that the two clinical types emerge from different pathophysiological episodes during the early development (40). Thus, neurological cretinism with irreversible neurological deficits has been interpreted as a consequence of maternal and fetal hypothyroxinemia during the pregnancy, whereas the symptoms of myxedematous cretinism are considered related to the duration and severity of postnatal hypothyroidism (40).

The structural and functional consequences of maternal thyroid dysfunction on the fetal brain development in humans have mainly been studied from indicators of altered brain development e.g. from neuropsychological testing of the children, from parent 
report or from follow-up on diagnosis or treatment of disease. However, recent studies have provided data on the morphological changes in the human brain in children exposed to abnormal maternal thyroid function in the pregnancy. Studies from Canada $(7,9,10)$ evaluated MRI scans of 20-30 children aged 9-14 years born to mothers who were treated with L-T4 in the pregnancy for previously or newly diagnosed hypothyroidism and matched controls. In these studies $(7,9,10)$, children born to mothers with hypothyroidism had smaller volume of the hippocampus, abnormal development of the corpus callosum and abnormal cortical morphology. Studies performed within the Generation R birth cohort in the Netherlands $(8,11)$ investigated MRI scans of 650 children aged 8 years. One study reported no association between maternal hypothyroxinemia and offspring brain morphology (8), whereas another recent study within the same cohort showed that both high and low fT4 was associated with lower grey matter and cortex volume and also with lower child IQ (11).

\section{Maternal thyroid dysfunction and offspring neurodevelopmental disorders}

The linkage between the brain abnormalities described after in utero exposure to maternal thyroid dysfunction and the abnormalities described in neurodevelopmental disorders will be exemplified below by seizure disorders and attention deficit hyperactivity disorder (ADHD).

The neurodevelopmental abnormalities described in seizure disorders include among other malformations of cortical development. These malformations are macroor microscopic abnormalities of the cerebral cortex that may result from abnormal proliferation, migration or synaptogenesis (41). Furthermore, alterations of the hippocampus have been considered a potential focus for the development of different types of seizure (42). Evidence from studies in animals support the hypothesis that maternal hypothyroidism in pregnancy may program the offspring to later development of seizure. In a study of rats (43), offspring exposed to maternal hypothyroidism during the pregnancy (induced by Methimazole) had an altered organization of the neocortex with abnormal migration and cytoarchitecture in the somatosensory cortex and in hippocampus. In addition to this, offspring exposed to maternal hypothyroidism in pregnancy were more likely to respond with seizure to an acoustic stimulus than the non-exposed (normal) rats; in another study, increasing dose of Propylthiouracil administered to pregnant rats was associated with longer duration of clonic seizures in the rat offspring (44).

Neurodevelopmental abnormalities associated with ADHD include structural alterations in the basal ganglia and in cortical thickness in frontal and parietotemporal regions and functional alterations within dopaminergic, noradrenergic and serotonergic neurotransmission (13, 45). Evidence from studies in animals and in humans support the hypothesis that maternal hyperthyroidism in pregnancy may program the offspring to later development of ADHD. In a recent experimental study (46), the effect of hyperthyroidism in the brain on behavior and hyperactivity was examined in a mouse model of type 3 deiodinase (DIO3) deficiency. DIO3 inactivates thyroid hormones and is highly expressed in the brain. Mice with DIO3 deficiency had high T3 levels in the brain, and responded with hyperactivity as well as decreased anxiety and depression-like behavior (46). In humans, ADHD symptoms have been strongly associated with generalized resistance to thyroid hormone caused by a mutation in the thyroid-receptor $\beta$ gene. In a study (47) of 18 families with a history of generalized resistance to thyroid hormone, affected and unaffected family members (children and adults) were evaluated by structured questionnaires for the presence of ADHD symptoms. Among adults and children, ADHD symptoms were much more frequent in individuals with generalized resistance to thyroid hormone than that in unaffected individuals. The thyroid receptor $\alpha(\mathrm{TR} \alpha)$ is the predominant receptor in the brain (48). TR $\alpha$ is exposed to high levels of thyroid hormone in patients with generalized resistance to thyroid hormone.

In Danish population-based studies $(49,50)$, we evaluated the hypothesis of fetal programing by maternal hypo- and hyperthyroidism (Fig. 2). We studied nearly 1.7 million children born in Denmark and followed them to the age of 30 years for the development of seizure (neonatal seizure, febrile seizure or epilepsy) and we studied nearly 850000 children born in Denmark and followed them to the age of 18 years for the diagnosis of ADHD. Notably, children born to mothers who were first time diagnosed and treated for thyroid disease in the years after the pregnancy had an increased risk of developing the neurodevelopmental disorders under study. It can be speculated if these women already suffered from some degree of thyroid dysfunction in the pregnancy, which at that point was undiagnosed and untreated. However, only indicators of exposure in pregnancy were available and more studies in humans, including studies with actual measurement of thyroid function in pregnancy, are needed to evaluate the association between maternal thyroid dysfunction 

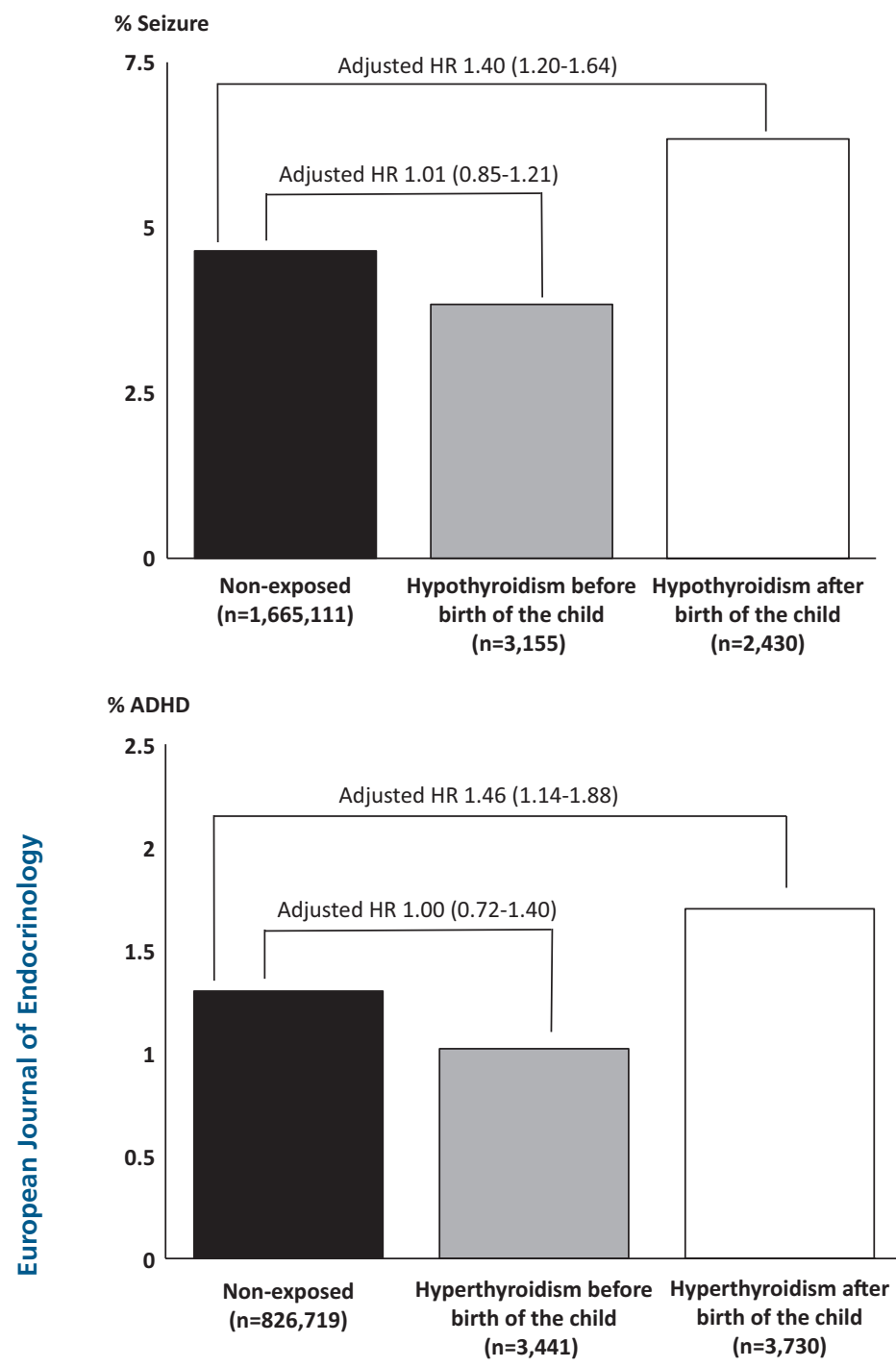

Figure 2

Observational studies in humans on maternal hypothyroidism in pregnancy and seizure in the offspring (upper figure) and maternal hyperthyroidism in pregnancy and attention deficit hyperactivity disorder (ADHD) in the offspring (lower figure). The figures illustrate the frequency of diagnosis of seizure or ADHD in the offspring during the follow-up. In non-exposed children (first column), the mother had no diagnosis of hypo- or hyperthyroidism before or after birth of the child. Children exposed were born to mothers diagnosed before birth of the child (middle column) or first time diagnosed in the 5-year period after birth of the child (last column).

Data are from Andersen et al. $(49,50)$.

and neurodevelopmental disorders in the offspring. In the Danish study, no increased risk of ADHD was observed in children born to mothers with hypothyroidism, but other observational studies have reported associations with maternal high thyroid-stimulating hormone (TSH) $(51,52)$, hypothyroxinemia (53), iodine deficiency (54) and the presence of thyroid peroxidase antibodies (55) illustrating the complexity of this association in an observational design, as discussed below.

\section{Methodological considerations}

All studies in humans evaluating the association between maternal thyroid dysfunction in pregnancy and specific neurodevelopmental disorders in the offspring were observational in design. Randomized controlled trials (RCTs) have been conducted with child IQ $(56,57)$ or pregnancy and perinatal complications (58) as outcomes. There are, however, ethical issues in the performance of RCTs in pregnant women as some testing may be considered unethical. This emphasizes the need for studies of different design.

Observational studies is an option that is typically cheaper and faster than RCTs, and it may seem as the ethically proper way of studying a specific research question. However, observational studies may reveal associations that should be interpreted carefully for the evaluation of causality (59) due to the various possible reasons (bias, confounding, chance) for an association observed (60).

Bias means that a measure of association is systematically wrong (60). Figure 3 illustrates the hypothesis of fetal programing by maternal thyroid dysfunction from a methodological point of view. Selection bias may arise from the composition of the study population at the exposure level if exposed and non-exposed participants differ systematically in a way that is related to the outcome. In studies of individuals with thyroid disease, such bias may arise if the patients included are selected in a hospital setting and the propensity of referral to hospital differ by age or by the severity of the disease $(61,62)$. Information bias has to do with the study definition of exposure and outcome (Fig. 3). For maternal thyroid disease, the timing of exposure in pregnancy and the timing of treatment may play a role as well as the reference ranges used for classification of maternal thyroid dysfunction. Recently, we showed that the reference range for TSH in early pregnancy varied widely (63) and in line with other studies $(64,65,66)$, we observed a high TSH in the very early pregnancy weeks. If method- and pregnancy-week specific reference ranges are not applied, this may introduce bias. For the outcome of neurodevelopmental disorders, the frequency of the disorders differs by age group, and the age of the child 
Exposure: Maternal thyroid dysfunction in pregnancy
Potential intermediates: Preterm birth? Birth weight?

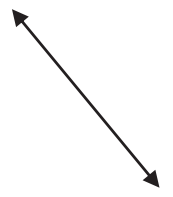

Potential confounders:

Maternal smoking?

Maternal psychiatric disease?

Endocrine disrupting chemicals?

Figure 3

Illustration of the hypothesis of fetal programing by maternal thyroid dysfunction from a methodological point of view. Interpretation of causality in observational studies may be challenged by definition of exposure and outcome as well as potential confounding factors and intermediates.

at the time of outcome evaluation as well as the method used for outcome assessment may vary considerably between studies (67).

Confounding can arise when an extraneous factor is related to the exposure and to the outcome, and is not an intermediate between the exposure and the outcome (Fig. 3). Since the etiology of both maternal thyroid disease and neurodevelopmental disorders is considered multifactorial, observational studies are prone to confounding. One possible confounder is maternal smoking in pregnancy (Fig. 3). Smoking has been associated with an increased risk of hyperthyroidism and may protect against the development of hypothyroidism (68). Furthermore, maternal smoking in pregnancy has been considered a risk factor for neurodevelopmental disorders in the offspring (13). Other possible environmental factors include the group of endocrine disrupting chemicals e.g. persistent organic pollutants and flame retardants (Fig. 3). Such chemicals may interfere with thyroid function (69), and they have also been considered risk factors for neurodevelopmental disorders in the offspring (70). Finally, psychiatric disease in the parents may introduce confounding (Fig. 3). Psychiatric disease and thyroid disease may coincide (71), and parental psychiatric disease may also associate with the development of disease in the offspring (72).

Intermediate factors are on the causal pathway from the exposure to the outcome (Fig. 3). Maternal thyroid dysfunction is associated with pregnancy complications including an increased risk of preterm birth and deviations in birth weight (73). Thus, it can be speculated if an increased risk of neurodevelopmental disorders in children born to mothers with thyroid dysfunction is mediated via pregnancy complications. Another area of debate is the distinction between abnormal maternal thyroid hormone levels in pregnancy and thyroid autoimmunity per se. Thyroid autoimmunity can be considered the main exposure, an intermediate, or both. The mechanisms by which thyroid autoantibodies may complicate a pregnancy (e.g. direct toxic effect, genetic autoimmune predisposure, higher TSH) are still controversial (74). One way to address the potential role of genetics in observational studies is to study the association with exposure to paternal disease. In Danish population-based studies $(49,50,71)$, we found no association between paternal thyroid dysfunction and neurodevelopmental disorders in the offspring, which may contradict a genetic component to some extent. The diversity in time of maternal onset of disease (Fig. 2) may also suggest that a consistently present genetic factor was not the main mechanism involved.

\section{Perspectives}

The molecular mechanisms for an in utero programing effect of different maternal conditions are still poorly understood. Focus has been on the role of epigenetic determinants (75). Thyroid hormones exert their crucial role during the fetal brain development via the regulation of gene expression (37), which indicates that epigenetic mechanisms may also be involved in fetal programing via maternal thyroid dysfunction.

The hypothesis of fetal programing by maternal thyroid dysfunction via disturbed early fetal brain development and later onset of neurodevelopmental disorders appears biologically plausible, which was one of the well-known viewpoints of Sir Bradford Hill in the evaluation of a causal relationship (59). Results from 
experimental studies have demonstrated developmental structural and/or functional defects after exposure to maternal thyroid dysfunction in pregnancy that may overlap with the developmental abnormalities described in neurodevelopmental disorders, and identified genes involved in the brain development that are regulated by T3 (37). Results from human observational studies are intriguing to interpret, and further studies are needed to determine and support other viewpoints of causality e.g. strength, specificity and consistency (59).

An important aspect to consider is the plasticity of the developing brain (36). The susceptibility of later development of disease in children exposed in utero to maternal thyroid dysfunction is likely to interact with the postnatal environment (Fig. 1), and structural alterations induced during the fetal brain development may be recovered by brain plasticity provided that all factors in the postnatal environment are favorable.

\section{Declaration of interest}

The authors declare that there is no conflict of interest that could be perceived as prejudicing the impartiality of this review.

\section{Funding}

This research did not receive any specific grant from any funding agency in the public, commercial or not-for-profit sector.

\section{Acknowledgements}

The authors dedicate this review to Prof. Peter Laurberg who tragically passed away on June 20, 2016. Prof. Peter Laurberg had a long-lasting and intense interest in the field of thyroid disease and pregnancy, and he participated in the initial work with the present review and in the discussion of the concept of fetal programing by maternal thyroid dysfunction. His contributions were invaluable and will be greatly missed.

\section{References}

1 Bernal J \& Nunez J. Thyroid hormones and brain development. European Journal of Endocrinology 1995133 390-398. (doi:10.1530/ eje.0.1330390)

2 Moog NK, Entringer S, Heim C, Wadhwa PD, Kathmann N \& Buss C. Influence of maternal thyroid hormones during gestation on fetal brain development. Neuroscience 2017342 68-100. (doi:10.1016/j. neuroscience.2015.09.070)

3 Kimura-Kuroda J, Nagata I, Negishi-Kato M \& Kuroda Y. Thyroid hormone-dependent development of mouse cerebellar Purkinje cells in vitro. Brain Research: Developmental Brain Research 2002137 55-65. (doi:10.1016/S0165-3806(02)00408-X)

4 Horn S, Kersseboom S, Mayerl S, Muller J, Groba C, Trajkovic-Arsic M, Ackermann T, Visser TJ \& Heuer H. Tetrac can replace thyroid hormone during brain development in mouse mutants deficient in the thyroid hormone transporter mct8. Endocrinology $2013 \mathbf{1 5 4}$ 968-979. (doi:10.1210/en.2012-1628)

5 Ahmed OM, Abd El-Tawab SM \& Ahmed RG. Effects of experimentally induced maternal hypothyroidism and hyperthyroidism on the development of rat offspring: I. The development of the thyroid hormones-neurotransmitters and adenosinergic system interactions. International Journal of Developmental Neuroscience 201028 437-454. (doi:10.1016/j.ijdevneu.2010.06.007)

6 Chen ZP \& Hetzel BS. Cretinism revisited. Best Practice and Research: Clinical Endocrinology and Metabolism 201024 39-50. (doi:10.1016/j. beem.2009.08.014)

7 Willoughby KA, McAndrews MP \& Rovet J. Effects of maternal hypothyroidism on offspring hippocampus and memory. Thyroid 201324 576-584. (doi:10.1089/thy.2013.0215)

8 Ghassabian A, El Marroun H, Peeters RP, Jaddoe VW, Hofman A, Verhulst FC, Tiemeier H \& White T. Downstream effects of maternal hypothyroxinemia in early pregnancy: nonverbal IQ and brain morphology in school-age children. Journal of Clinical Endocrinology and Metabolism 201499 2383-2390. (doi:10.1210/ jc.2013-4281)

9 Samadi A, Skocic J \& Rovet JF. Children born to women treated for hypothyroidism during pregnancy show abnormal corpus callosum development. Thyroid 201525 494-502. (doi:10.1089/ thy.2014.0548)

10 Lischinsky JE, Skocic J, Clairman H \& Rovet J. Preliminary findings show maternal hypothyroidism may contribute to abnormal cortical morphology in offspring. Frontiers in Endocrinology 2016716. (doi:10.3389/fendo.2016.00016)

11 Korevaar TI, Muetzel R, Medici M, Chaker L, Jaddoe VW, de Rijke YB, Steegers EA, Visser TJ, White T, Tiemeier H et al. Association of maternal thyroid function during early pregnancy with offspring IQ and brain morphology in childhood: a population-based prospective cohort study. Lancet: Diabetes and Endocrinology $2016435-43$. (doi:10.1016/s2213-8587(15)00327-7)

12 Little J. Epidemiology of neurodevelopmental disorders in children. Prostaglandins, Leukotrienes, and Essential Fatty Acids 200063 11-20. (doi:10.1054/plef.2000.0185)

13 Thapar A \& Cooper M. Attention deficit hyperactivity disorder. Lancet 2016387 1240-1250. (doi:10.1016/S0140-6736(15)00238-X)

14 Susser E, Hoek HW \& Brown A. Neurodevelopmental disorders after prenatal famine: the story of the Dutch Famine Study. American Journal of Epidemiology 1998147 213-216. (doi:10.1093/ oxfordjournals.aje.a009439)

15 Forsdahl A. Are poor living conditions in childhood and adolescence an important risk factor for arteriosclerotic heart disease? British Journal of Preventive and Social Medicine 1977 31 91-95.

16 Barker DJ, Winter PD, Osmond C, Margetts B \& Simmonds SJ. Weight in infancy and death from ischaemic heart disease. Lancet 19892 577-580. (doi:10.1016/S0140-6736(89)90710-1)

17 Hales CN \& Barker DJ. Type 2 (non-insulin-dependent) diabetes mellitus: the thrifty phenotype hypothesis. Diabetologia 199235 595-601. (doi:10.1007/BF00400248)

18 Kyle UG \& Pichard C. The Dutch Famine of 1944-1945: a pathophysiological model of long-term consequences of wasting disease. Current Opinion in Clinical Nutrition and Metabolic Care 20069 388-394. (doi:10.1097/01.mco.0000232898.74415.42)

19 Li Y, He Y, Qi L, Jaddoe VW, Feskens EJ, Yang X, Ma G \& Hu FB. Exposure to the Chinese famine in early life and the risk of hyperglycemia and type 2 diabetes in adulthood. Diabetes 201059 2400-2406. (doi:10.2337/db10-0385)

20 Ekbom A, Trichopoulos D, Adami HO, Hsieh CC \& Lan SJ. Evidence of prenatal influences on breast cancer risk. Lancet $1992 \mathbf{3 4 0}$ 1015-1018. (doi:10.1016/0140-6736(92)93019-J)

21 Fraser A \& Lawlor DA. Long-term health outcomes in offspring born to women with diabetes in pregnancy. Current Diabetes Reports 2014 14 489. (doi:10.1007/s11892-014-0489-x)

22 Berry DC, Boggess K \& Johnson QB. Management of pregnant women with type 2 diabetes mellitus and the consequences of fetal programming in their offspring. Current Diabetes Reports 20161636. (doi:10.1007/s11892-016-0733-7) 
23 Reynolds RM. Glucocorticoid excess and the developmental origins of disease: two decades of testing the hypothesis - 2012 Curt Richter Award Winner. Psychoneuroendocrinology 201338 1-11. (doi:10.1016/j. psyneuen.2012.08.012)

24 Entringer S, Buss C \& Wadhwa PD. Prenatal stress, development, health and disease risk: a psychobiological perspective-2015 Curt Richter Award Paper. Psychoneuroendocrinology 201562 366-375. (doi:10.1016/j.psyneuen.2015.08.019)

25 Phillips DI, Cooper C, Fall C, Prentice L, Osmond C, Barker DJ \& Rees Smith B. Fetal growth and autoimmune thyroid disease. Quarterly Journal of Medicine 199386 247-253. (doi:10.5001/omj.2015.84)

26 Phillips DI, Barker DJ \& Osmond C. Infant feeding, fetal growth and adult thyroid function. Acta Endocrinologica 1993129 134-138. (doi:10.1530/acta.0.1290134)

27 Brix TH, Kyvik KO \& Hegedus L. Low birth weight is not associated with clinically overt thyroid disease: a population based twin casecontrol study. Clinical Endocrinology 200053 171-176. (doi:10.1046/ j.1365-2265.2000.01025.x)

28 Brix TH, Hansen PS, Rudbeck AB, Hansen JB, Skytthe A, Kyvik $\mathrm{KO} \&$ Hegedus L. Low birth weight is not associated with thyroid autoimmunity: a population-based twin study. Journal of Clinical Endocrinology and Metabolism 200691 3499-3502. (doi:10.1210/ jc.2006-1348)

29 Frost M, Petersen I, Hegedus L, Christiansen L, Brix T \& Christensen $\mathrm{K}$. Regulation of the pituitary-thyroid axis in adulthood is not related to birth weight: evidence from extremely birth weightdiscordant monozygotic Danish twin pairs. Thyroid 201323 785-790. (doi:10.1089/thy.2012.0095)

30 Mittag J, Lyons DJ, Sallstrom J, Vujovic M, Dudazy-Gralla S, Warner A, Wallis K, Alkemade A, Nordstrom K, Monyer H et al. Thyroid hormone is required for hypothalamic neurons regulating cardiovascular functions. Journal of Clinical Investigation $2013 \mathbf{1 2 3}$ 509-516. (doi:10.1172/JCI65252)

31 Godoy GA, Korevaar TI, Peeters RP, Hofman A, de Rijke YB, BongersSchokking JJ, Tiemeier H, Jaddoe VW \& Gaillard R. Maternal thyroid hormones during pregnancy, childhood adiposity and cardiovascular risk factors: the Generation R Study. Clinical Endocrinology 201481 117-125. (doi:10.1111/cen.12399)

32 Grattan MJ, Thomas DS, Hornberger LK, Hamilton RM, Midodzi WK \& Vohra S. Maternal hypothyroidism may be associated with CHD in offspring. Cardiology in the Young 201525 1247-1253. (doi:10.1017/ S1047951114001887)

33 Rytter D, Andersen SL, Bech BH, Halldorsson TI, Henriksen TB, Laurberg P \& Olsen SF. Maternal thyroid function in pregnancy may program offspring blood pressure, but not adiposity at $20 \mathrm{y}$ of age. Pediatric Research 201680 7-13. (doi:10.1038/pr.2016.56)

34 Vulsma T, Gons MH \& de Vijlder JJ. Maternal-fetal transfer of thyroxine in congenital hypothyroidism due to a total organification defect or thyroid agenesis. New England Journal of Medicine 1989321 13-16. (doi:10.1056/NEJM198907063210103)

35 Morreale de Escobar G, Obregon MJ \& Escobar del Rey F. Is neuropsychological development related to maternal hypothyroidism or to maternal hypothyroxinemia? Journal of Clinical Endocrinology and Metabolism 200085 3975-3987. (doi:10.1210/jc.85.11.3975)

36 Ismail FY, Fatemi A \& Johnston MV. Cerebral plasticity: windows of opportunity in the developing brain. European Journal of Paediatric Neurology 201721 23-48. (doi:10.1016/j.ejpn.2016.07.007)

37 Bernal J. Thyroid hormone regulated genes in cerebral cortex development. Journal of Endocrinology 2017232 R83-R97. (doi:10.1530/JOE-16-0424)

38 Gil-Ibanez P, Bernal J \& Morte B. Thyroid hormone regulation of gene expression in primary cerebrocortical cells: role of thyroid hormone receptor subtypes and interactions with retinoic acid and glucocorticoids. PLOS ONE 20149 e91692. (doi:10.1371/journal. pone.0091692)
39 Gil-Ibanez P, Garcia-Garcia F, Dopazo J, Bernal J \& Morte B. Global transcriptome analysis of primary cerebrocortical cells: identification of genes regulated by triiodothyronine in specific cell types. Cerebral Cortex 201727 706-717. (doi:10.1093/cercor/bhv273)

40 Boyages SC \& Halpern JP. Endemic cretinism: toward a unifying hypothesis. Thyroid 19933 59-69. (doi:10.1089/thy.1993.3.59)

41 Bozzi Y, Casarosa S \& Caleo M. Epilepsy as a neurodevelopmental disorder. Frontiers in Psychiatry 20123 19. (doi:10.3389/ fpsyt.2012.00019)

42 Sisodiya S. Feverish prospects for seizure genetics. Nature Genetics 201446 1255-1256. (doi:10.1038/ng.3150)

43 Auso E, Lavado-Autric R, Cuevas E, Del Rey FE, Morreale De Escobar G $\&$ Berbel P. A moderate and transient deficiency of maternal thyroid function at the beginning of fetal neocorticogenesis alters neuronal migration. Endocrinology 2004145 4037-4047. (doi:10.1210/en.20040274)

44 Gilbert ME, Ramos RL, McCloskey DP \& Goodman JH. Subcortical band heterotopia in rat offspring following maternal hypothyroxinaemia: structural and functional characteristics. Journal of Neuroendocrinology 201426 528-541. (doi:10.1111/jne.12169)

45 Gallo EF \& Posner J. Moving towards causality in attentiondeficit hyperactivity disorder: overview of neural and genetic mechanisms. Lancet Psychiatry 20163 555-567. (doi:10.1016/S22150366(16)00096-1)

46 Stohn JP, Martinez ME \& Hernandez A. Decreased anxiety- and depression-like behaviors and hyperactivity in a type 3 deiodinasedeficient mouse showing brain thyrotoxicosis and peripheral hypothyroidism. Psychoneuroendocrinology 201674 46-56. (doi:10.1016/j.psyneuen.2016.08.021)

47 Hauser P, Zametkin AJ, Martinez P, Vitiello B, Matochik JA, Mixson AJ \& Weintraub BD. Attention deficit-hyperactivity disorder in people with generalized resistance to thyroid hormone. New England Journal of Medicine 1993328 997-1001. (doi:10.1056/ NEJM199304083281403)

48 Bernal J. Thyroid hormone receptors in brain development and function. Nature Clinical Practice Endocrinology and Metabolism 20073 249-259. (doi:10.1038/ncpendmet0424)

49 Andersen SL, Laurberg P, Wu CS \& Olsen J. Maternal thyroid dysfunction and risk of seizure in the child: a Danish nationwide cohort study. Journal of Pregnancy 20132013636705 (doi:10.1155/2013/636705)

50 Andersen SL, Laurberg P, Wu CS \& Olsen J. Attention deficit hyperactivity disorder and autism spectrum disorder in children born to mothers with thyroid dysfuntion: a Danish nationwide cohort study. BJOG 2014121 1365-1374. (doi:10.1111/14710528.12681)

51 Haddow JE, Palomaki GE, Allan WC, Williams JR, Knight GJ, Gagnon J, O'Heir CE, Mitchell ML, Hermos RJ, Waisbren SE et al. Maternal thyroid deficiency during pregnancy and subsequent neuropsychological development of the child. New England Journal of Medicine 1999341 549-555. (doi:10.1056/NEJM199908193410801)

52 Pakkila F, Mannisto T, Pouta A, Hartikainen AL, Ruokonen A, Surcel HM, Bloigu A, Vaarasmaki M, Jarvelin MR, Moilanen I et al. The impact of gestational thyroid hormone concentrations on ADHD symptoms of the child. Journal of Clinical Endocrinology and Metabolism 201499 E1-E8. (doi:10.1210/jc.2013-2943)

53 Modesto T, Tiemeier H, Peeters RP, Jaddoe VW, Hofman A, Verhulst FC \& Ghassabian A. Maternal mild thyroid hormone insufficiency in early pregnancy and attention-deficit/hyperactivity disorder symptoms in children. JAMA Pediatrics 2015169 838-845. (doi:10.1001/jamapediatrics.2015.0498)

54 Vermiglio F, Lo Presti VP, Moleti M, Sidoti M, Tortorella G, Scaffidi G, Castagna MG, Mattina F, Violi MA, Crisa A et al. Attention deficit and hyperactivity disorders in the offspring of mothers exposed to mild-moderate iodine deficiency: a possible novel iodine deficiency 
disorder in developed countries. Journal of Clinical Endocrinology and Metabolism 200489 6054-6060. (doi:10.1210/jc.2004-0571)

55 Ghassabian A, Bongers-Schokking JJ, de Rijke YB, van Mil N, Jaddoe VW, de Muinck Keizer-Schrama SM, Hooijkaas H, Hofman A, Visser W, Roman GC et al. Maternal thyroid autoimmunity during pregnancy and the risk of attention deficit/hyperactivity problems in children: the Generation R Study. Thyroid 201222 178-186. (doi:10.1089/thy.2011.0318)

56 Lazarus JH, Bestwick JP, Channon S, Paradice R, Maina A, Rees R, Chiusano E, John R, Guaraldo V, George LM et al. Antenatal thyroid screening and childhood cognitive function. New England Journal of Medicine 2012366 493-501. (doi:10.1056/NEJMoa1106104)

57 Casey BM. Effect of treatment of maternal subclinical hypothyroidism or hypothyroxinemia on IQ in offspring. American Journal of Obstetrics and Gynecology 2016214 S2. (doi:10.1016/j.ajog.2015.10.023)

58 Negro R, Schwartz A, Gismondi R, Tinelli A, Mangieri T \& StagnaroGreen A. Universal screening versus case finding for detection and treatment of thyroid hormonal dysfunction during pregnancy. Journal of Clinical Endocrinology and Metabolism 201095 1699-1707. (doi:10.1210/jc.2009-2009)

59 Hill AB. The environment and disease: association or causation? Proceedings of the Royal Society of Medicine 196558 295-300.

60 Jepsen P, Johnsen SP, Gillman MW \& Sorensen HT. Interpretation of observational studies. Heart 200490 956-960. (doi:10.1136/ hrt.2003.017269)

61 Carle A, Laurberg P, Pedersen IB, Knudsen N, Perrild H, Ovesen L, Rasmussen LB \& Jorgensen T. Mainly the younger hypothyroid patients are referred to hospital - evidence for referral bias. Journal of Clinical Epidemiology 200962 446-451. (doi:10.1016/j. jclinepi.2008.06.016)

62 Carle A, Pedersen IB, Perrild H, Ovesen L, Jorgensen T \& Laurberg P. High age predicts low referral of hyperthyroid patients to specialized hospital departments: evidence for referral bias. Thyroid 201323 1518-1524. (doi:10.1089/thy.2013.0074)

63 Laurberg P, Andersen SL, Hindersson P, Nohr EA \& Olsen J. Dynamics and predictors of serum TSH and fT4 reference limits in early pregnancy: a study within the Danish National Birth Cohort. Journal of Clinical Endocrinology and Metabolism 2016101 2484-2492. (doi:10.1210/jc.2016-1387)

64 Dashe JS, Casey BM, Wells CE, McIntire DD, Byrd EW, Leveno KJ \& Cunningham FG. Thyroid-stimulating hormone in singleton and twin pregnancy: importance of gestational age-specific reference ranges. Obstetrics and Gynecology 2005106 753-757. (doi:10.1097/01. AOG.0000175836.41390.73)

65 Mannisto T, Surcel HM, Ruokonen A, Vaarasmaki M, Pouta A, Bloigu A, Jarvelin MR, Hartikainen AL \& Suvanto E. Early pregnancy reference intervals of thyroid hormone concentrations in a thyroid antibody-negative pregnant population. Thyroid 201121 291-298. (doi:10.1089/thy.2010.0337)

66 Li C, Shan Z, Mao J, Wang W, Xie X, Zhou W, Li C, Xu B, Bi L, Meng $\mathrm{T}$ et al. Assessment of thyroid function during first-trimester pregnancy: what is the rational upper limit of serum TSH during the first trimester in Chinese pregnant women? Journal of Clinical Endocrinology and Metabolism 201499 73-79. (doi:10.1210/jc.2013-1674)

67 Andersen SL, Olsen J \& Laurberg P. Foetal programming by maternal thyroid disease. Clinical Endocrinology 201581 126-133. (doi:10.1111/ cen.12415)

68 Andersen SL, Olsen J, Wu CS \& Laurberg P. Smoking reduces the risk of hypothyroidism and increases the risk of hyperthyroidism: evidence from 450,842 mothers giving birth in Denmark. Clinical Endocrinology 201480 307-314. (doi:10.1111/cen.12279)

69 Hartoft-Nielsen ML, Boas M, Bliddal S, Rasmussen AK, Main K \& Feldt-Rasmussen U. Do thyroid disrupting chemicals influence foetal development during pregnancy? Journal of Thyroid Research 2011 2011 342189. (doi:10.4061/2011/342189)

70 Liew Z, Ritz B, von Ehrenstein OS, Bech BH, Nohr EA, Fei C, Bossi R, Henriksen TB, Bonefeld-Jorgensen EC \& Olsen J. Attention deficit/ hyperactivity disorder and childhood autism in association with prenatal exposure to perfluoroalkyl substances: a nested case-control study in the Danish National Birth Cohort. Environmental Health Perspectives 2015123 367-373. (doi:10.1289/ehp.1408412)

71 Andersen SL, Olsen J, Wu CS \& Laurberg P. Psychiatric disease in late adolescence and young adulthood. Foetal programming by maternal hypothyroidism? Clinical Endocrinology 201481 126-133. (doi:10.1111/cen.12415)

72 McLaughlin KA, Gadermann AM, Hwang I, Sampson NA, Al-Hamzawi A, Andrade LH, Angermeyer MC, Benjet C, Bromet EJ, Bruffaerts $\mathrm{R}$ et al. Parent psychopathology and offspring mental disorders: results from the WHO World Mental Health Surveys. British Journal of Psychiatry 2012200 290-299. (doi:10.1192/bjp.bp.111.101253)

73 Andersen SL, Olsen J, Wu CS \& Laurberg P. Low birth weight in children born to mothers with hyperthyroidism and high birth weight in hypothyroidism, whereas preterm birth is common in both conditions: a Danish National Hospital Register study. European Thyroid Journal 20132 135-144. (doi:10.1159/000350513)

74 Prummel MF \& Wiersinga WM. Thyroid autoimmunity and miscarriage. European Journal of Endocrinology 2004150 751-755. (doi:10.1530/eje.0.1500751)

75 Reynolds RM, Jacobsen GH \& Drake AJ. What is the evidence in humans that DNA methylation changes link events in utero and later life disease? Clinical Endocrinology 201378 814-822. (doi:10.1111/ cen.12164)

Received 18 November 2016

Revised version received 28 February 2017

Accepted 4 April 2017 